NBER WORKING PAPER SERIES

\title{
COMPETITION IN IMPERFECT MARKETS: DOES IT HELP CALIFORNIA'S MEDICAID MOTHERS?
}

\author{
Anna Aizer \\ Janet Currie \\ Enrico Moretti \\ Working Paper 10429 \\ http://www.nber.org/papers/w10429 \\ NATIONAL BUREAU OF ECONOMIC RESEARCH \\ 1050 Massachusetts Avenue \\ Cambridge, MA 02138 \\ April 2004
}

The authors thank Cairan Phibbs for generously providing data on neonatal intensive care units, and we thank seminar participants at the University of Kentucky and Princeton University and Jeffrey Kling and W. Bentley MacLeod for helpful comments. Currie also thanks the Center for Health and Well-Being at Princeton University for support while this paper was being written. The authors are grateful for support from National Science Foundation, grant \#NSF 0241861, but remain solely responsible for its contents. Benjamin Bolitzer and Yan Lee provided excellent research assistance. The views expressed herein are those of the author(s) and not necessarily those of the National Bureau of Economic Research.

(C2004 by Anna Aizer, Janet Currie, and Enrico Moretti. All rights reserved. Short sections of text, not to exceed two paragraphs, may be quoted without explicit permission provided that full credit, including (C) notice, is given to the source. 
Competition in Imperfect Markets: Does it Help California's Medicaid Mothers?

Anna Aizer, Janet Currie, and Enrico Moretti

NBER Working Paper No. 10429

April 2004

JEL No. I11, I12, I18

\section{ABSTRACT}

Poor and uneducated patients may not know what health care is desirable and, if fully insured, have little incentive to minimize the costs of their care. Partly in response to these concerns, most states have moved a substantial portion of their Medicaid caseloads out of traditional competitive fee-for-service (FFS) care, and into mandatory managed care (MMC) plans that severely restrict the choice of provider.

We use a unique longitudinal data base of California births in order to examine the impact of this policy on pregnant women and infants. California phased in MMC creating variation in the timing of MMC. We identify the effects of MMC using changes in the regime faced by individual mothers between births. Some counties adopted single-carrier plans, while others adopted regimes with at least two carriers. Hence, we also ask whether competition between at least two carriers improved MMC outcomes. We find that MMC reduced the quality of prenatal care and increased low birth weight, prematurity, and neonatal death. Our results suggest that the competitive FFS system provided better care than the new MMC system, and that requiring the participation of at least two plans did not improve matters.

$\begin{array}{lll}\text { Anna Aizer } & \text { Janet Currie } & \text { Enrico Moretti } \\ \text { Department of Economics } & \text { Department of Economics } & \text { Department of Economics } \\ \text { Brown University } & \text { UCLA } & \text { UCLA } \\ \text { Box B, 64 Waterman Street } & \text { 405 Hilgard Avenue } & \text { 405 Hilgard Avenue } \\ \text { Providence, RI 02912 } & \text { Los Angeles, CA 90095-1477 } & \text { Los Angeles, CA 90095-1477 } \\ \text { anna_aizer@brown.edu } & \text { and NBER } & \text { and NBER } \\ & \text { currie@simba.sscnet.ucla.edu } & \text { moretti@econ.ucla.edu }\end{array}$


There is a vast literature focusing on imperfections in the market for health care. ${ }^{1}$ In the case of public health insurance for the indigent, it has been argued that poor and uneducated patients may be even less likely than others to know what health care is really desirable, and that if these patients are fully insured by public plans, then they will have little incentive to minimize the costs of their medical care. Hence, poor people were thought to be easy marks for shady providers who billed government for many services of dubious quality (e.g. “Medicaid Mills”); were more likely than others to use high cost providers such as emergency rooms rather than lower cost providers such as doctors' offices; and were less likely than others to receive preventive care.

In the U.S., Medicaid is the main public health insurance program for low income women and children. Over the 1990s, most states moved a substantial portion of their Medicaid caseloads out of traditional competitive fee-for-service (FFS) care, and into mandatory managed care (MMC) plans. ${ }^{2}$ State governments argued that this change would improve access to care, and the quality of care for Medicaid patients, by linking patients to approved providers. In contrast to FFS, in which patients may chose any provider willing to serve them, MMC plans typically severely restrict the choice of provider, and pay the provider(s) a fixed (capitated) fee per patient.

This feature of MMC removed Medicaid providers from the discipline of the market by

${ }^{1}$ For example, many chapters in the Handbook of Health Economics (Culyer and Newhouse, 2000) deal with this issue, and Glied (2000) discusses it in the context of managed care organizations.

${ }^{2}$ In this way, Medicaid patients became more similar to the majority of the privately insured, who had already become subject to managed care-by 1992, about 70\% of the privately insured were already in managed care plans (Glied, 2000). 
giving them a largely captive patient base. Patient advocates point out that in contrast to FFS providers, capitated MMC plans have incentives to minimize costs by providing as little care as possible, and by discouraging the sickest patients from enrolling in the plans. These are the same concerns that have been expressed with respect to privately enrolled patients in managed care plans.

In this paper, we use a unique longitudinal data base of California births in order to examine the impact of switching from a competitive FFS system to MMC on the utilization of care and outcomes among the disadvantaged pregnant women who became subject to MMC. This file is formed by using the confidential birth records to link mothers between births. Beginning in 1994, California phased in MMC on a county-by-county basis, creating a great deal of variation in the timing of MMC which we exploit. We control for individual heterogeneity using mother fixed effects and identify the effects of the different plans by focusing on changes in the Medicaid regime faced by a mother between births. This strategy allows us to overcome one of the key weaknesses of earlier studies, which is that Medicaid mothers may differ from other mothers in unobserved ways, and that MMC may change the way that mothers are selected into the Medicaid program.

A second feature of California's MMC implementation is that while some counties adopted a single-insurance-carrier plan, the state mandated that others adopt regimes with at least two carriers. It was thought that mandating at least two competing plans would help to assure quality by allowing patients unhappy with one plan to "vote with the feet" and move to the other plan. We therefore ask whether mandating the participation of more than one carrier improved MMC outcomes. 
In contrast to previous examinations of MMC which have found some evidence of effects on health care utilization but little evidence of effects on health outcomes, we find that MMC plans were associated with reductions in the quality of prenatal care and increases in low birth weight, prematurity, and neonatal death relative to FFS Medicaid. The difference in results may be due to the fact that our study design overcomes many of the limitations of previous work. By following the same mothers over time and examining changes in the enrollment patterns, utilization of care, and birth outcomes of mothers who became subject to different types of MMC, we are better able to isolate the effects of these plans. By focusing on the population that was actually subject to MMC, we avoid drawing inferences about its effects from the experiences of the large numbers of women who were not required to enroll. And by merging data from several sources, we are able to examine a wide range of outcomes, and to judge whether the estimated effects are consistent across these outcomes.

Our estimates are robust to several changes in specification including: a "regression discontinuity" design in which we focus only on women who had a birth in the three years before or after a change in MMC; an "intent-to-treat” design in which we assign MMC status based on the state's original plan for each county (disregarding changes in MMC which were not in the state plan); controlling for the endogeneity of location by assigning MMC status to each women based on the first county in which she is observed only; and including both both county-specific time trends and time trends interacted with the mother's demographic characteristics. We also show that while MMC has strong effects on the target group, it had no effect on other similar groups who were not subject to MMC.

Our results suggest that despite its well-documented failings, the old, competitive, fee- 
for-service system with many atomistic providers of Medi-Cal services provided care that was better in many respects than either MMC system. Moreover attempts to mandate a degree of competition by requiring the participation of at least two plans did little to improve matters. Ultimately, it appears that these poor, uneducated women did a better job of navigating the FFS health care system than the government was able to do for them.

The rest of the paper is organized as follows: Section 1 provides background about the implementation of MMC in California. Section 2 describes our data sources, and section 3 lays out our methods. Results are discussed in section 4, and section 5 concludes.

\section{Background}

a) The Implementation of Medicaid Managed Care in California

Until 1994, the vast majority of California's Medicaid recipients were in fee-for-service plans in which recipients could choose any provider who would accept them, and providers would then seek reimbursement from Medi-Cal, California’s Medicaid agency. Several counties had managed care plans available to Medi-Cal recipients on a voluntary basis, but enrollments in these plans were very small. Although two California counties (Santa Barbara and San Mateo) were allowed to implement experimental mandatory MMC plans, it was not until the early 1990s that the state made definitive moves in this direction. ${ }^{3}$ It was first necessary to pass state enabling legislation, and to obtain a waiver of the federal government's requirement that Medicaid patients be allowed a choice of providers.

${ }^{3}$ Tai-Seale et al. (2001) find that these two counties had lower utilization of prenatal care, and a higher number of one-day stays compared to a third county with FFS care. 
MMC was adopted according to The Department of Health Services' Plan for Expanding Medi-Cal Managed Care (DHS, 1993). In the cover letter to this document, the director of the Department of Health Services, Molly Joel Coye, laid out the case for an expansion of mandatory managed care in California as follows:

"The care our patients receive is fragmented, patchwork, and out-dated. Instead of being cared for in a doctor's office or a clinic, our patients wind up waiting hours in emergency rooms for simple problems like a child's ear infection. Thousands of Medi-Cal beneficiaries are hospitalized each year for serious health conditions that could have been prevented by primary care...There is an alternative that makes sense: organized health care...Because the state is in such a severe budget crisis, many people assume that we are speeding up the transition to managed care in order to save money. But the purpose of our accelerated transition-designed to double managed care enrollments by April 1995 and to take nearly half of all Medi-Cal beneficiaries into managed care arrangements by the year 1996-is to improve quality and access" (Coye, 1993).

Whether the impetus for the expansion was cost savings or improving access to care, it seems clear that the primary impetus for the change came from the state rather than from individual counties.

Three main models of MMC are discussed in the planning document: the County Organized Health System (COHS); the Two-Plan Model; and the Geographic Managed Care (GMC) model. ${ }^{4}$ In a COHS county, there is one public, county-run Medicaid managed care plan, and people who are required to enroll in managed care must enroll in that plan if they wish to receive Medicaid services. In a Two-Plan County, there is a county-managed plan and a private managed care plan that has a contractual arrangement with the county to accept Medicaid

\footnotetext{
${ }^{4}$ Three small experimental managed care programs have been excluded from our analysis, Prepaid Health Plans, Primary Care Case Management, and Fee-For-Service Managed Care. In June 2001, these accounted for .02\%, .01\%, and .73\% of all Medi-Cal beneficiaries. The first two are voluntary managed care plans, while the last is a FFS plan in which the state contractor acts as a care-coordinator and gate-keeper.
} 
patients. People required to enroll in managed care must choose between the two plans. Finally, in a GMC county, there is no public, county-managed plan; the county contracts with different private managed care organizations to provide services to the Medicaid caseload. All private plans involved in MMC are selected by competitive bidding, and must offer a minimum bundle of services.

The planning document specified that 13 of California’s 58 counties would adopt MMC using the Two-Plan model, a further three counties (Orange, Santa Cruz and Solano) would adopt the COHS, and that GMC would be implemented in Sacramento. The main criteria for determining which counties would get which plan were the county's population (there had to be a minimum of 45,000 Medi-Cal beneficiaries) and the extent of private managed care infrastructure that already existed in the county at the time of the planning document. Given the small number of counties with GMC plans, we will look at Two Plan and GMC counties together in what follows.

The state plan inspired a great deal of controversy about what type of plan would best serve Medi-Cal recipients and other indigents. The state favored the Two-Plan model, which is why it mandated that it be adopted in most MMC counties. The state held that competition between plans would offer patients choice and assure quality. However, in federal Congressional hearings held to discuss the state’s plans, many stakeholders expressed reservations (Committee on Energy and Commerce, 1994).

It was feared that commercial plans would place new burdens on safety net providers by identifying the low-cost patients and leaving the rest for the safety net to serve, and by denying services to people so that they ended up in emergency rooms. For example, Michele Melden, an 
attorney with the National Health Law Program discussed one managed care organization that routinely "emergency disenrolled" members who were brought into the San Bernardino trauma unit, with the disenrollment being effective the date of injury (Committee on Energy and Commerce, page 44).

Witnesses also raised the possibility that diverting paying Medi-Cal patients from traditional safety-net providers to private plans would reduce the ability of these providers to care for non-paying, indigent patients, and that it would threaten the "disproportionate share" payments that these providers received from the federal government. One study in Sacramento found that community clinics experienced 40 to 45 percent declines in usage after the introduction of MMC (Korenbrot, Miller and Green, 1998).

In the end, events unfolded according to the state's plan: 12 of the 13 counties designated to adopt the Two-Plan model did so (San Diego eventually adopted the GMC model instead but in what follows we treat Two-Plan and GMC similarly). The three counties earmarked for COHS adopted it, as did two other counties, Napa and Monterey. (Yolo county also adopted COHS, but after our sample period). By June 2001, some 2.8 million people, half of those enrolled in Medi-Cal, were in managed care (Klein and Donaldson, 2002). Moreover, while counties had been asked to have their new plans in place by April 1996 at the latest, 15 of the 17 originally designated counties had implemented a plan by April 1997 (the two laggards were San Diego and Tulare). In general then, it appears that counties cooperated remarkably closely with the master plan that had been laid out by the state. ${ }^{5}$

${ }^{5}$ Some delay may have been difficult for counties to avoid. For example, Los Angeles county began planning to set up their Two-Plan model in February 1993, before the state plan had even been officially released. In Sept. 1994, the governor signed legislation enabling the 
Table 1 lists the counties that adopted MMC, the type of plan that they adopted, the date at which enrollment began, the fraction of the caseload enrolled in a privately-run plan as of July 2000, the size of the county as proxied by the number of births in 2000, and median household income in the county.

Table 1 shows that the counties that adopted MMC were much larger on average than those that did not, as one would expect given the rationale for selecting counties given in the state plan. COHS counties were somewhat wealthier than Two Plan/GMC counties, which in turn were wealthier than those that did not adopt. These differences suggest that it will be important to control for heterogeneity when examining the effects of MMC adoption on outcomes. Table 1 also shows that in a typical Two Plan county, between 20 to 40 percent of the caseload was enrolled in a private plan, so that the private plans were important, and might have been expected to provide some competition for the publicly run plans.

It is however, very important to note that some categories of pregnant women are not required to join managed care plans. The most important exceptions for our purposes are pregnant women eligible for Medicaid only because their incomes are above the threshold for cash welfare, but less than 200 percent of poverty, and undocumented pregnant women. ${ }^{6}$ In 2000, $11.6 \%$ of Medi-Cal deliveries were of women in the first category, while $38.9 \%$ of

creation of the county-managed plan. Creation of the plan was completed by Dec. 1995 and it was licensed to serve Medi-Cal eligibles in April 1997. However, it did not receive permission from the Health Care Financing Administration to move FFS beneficiaries into managed care until Sept. 1997 (www.lacare.org/ lacare/lacare01.nsf/0/9ef4e855697f82f68825688d005a4fb1? OpenDocument).

${ }^{6}$ Currie and Gruber (1996) discuss extensions of Medicaid eligibility to pregnant women who were not on cash assistance over the late 1980s and early 1990s. 
California Medicaid deliveries were of undocumented women (Rains, 2000). In general, women who were only eligible for Medi-Cal because they were pregnant, and who were only eligible for coverage of prenatal care and delivery, were not required to join managed care organizations.

In order to focus on women likely to be subject to MMC, we restrict our analysis sample to unmarried native-born women with a high school education or less. These criteria remove the undocumented (who by definition are foreign-born) and also remove the better-educated and/or married women who are likely to be eligible only because of the income criteria. ${ }^{7}$ By focusing on this disadvantaged population, we can also ask whether there were spillover effects of MMC on other disadvantaged women in Two-Plan counties, as critics of the scheme feared.

\section{b) Possible Effects of Medicaid Managed Care}

Under a traditional FFS plan, a provider receives payment for every service rendered. Hence, provided that reimbursements are set high enough to make the provision of services profitable, the provider will have an incentive to provide as many services as the patient will accept. The main feature of an MMC plan is that the plan receives a fixed payment for each patient. Thus, at any point in time, the plan has an incentive to provide as few services as possible, though to the extent that they are responsible for the same patient over time, they may

\footnotetext{
${ }^{7}$ It is unfortunate that we also lose foreign-born women who are legal residents, but it is impossible to determine from the data who is legal and who is not. Moreover, among foreignborn women language and culture may create additional barriers to care, and the growth in the undocumented category raises the possibility that foreign-born women who were otherwise ineligible for Medi-Cal presented themselves as undocumented in order to gain access to these services.
} 
also have an incentive to insure that patients receive effective preventive care. Plans receiving capitated payments also have a clear incentive to "dump" or "cream skim". That is, to discourage people who are likely to be costly patients from enrolling and instead target those who are likely to be inexpensive. Arlen and MacLeod (2003) point out that a third reason why managed care organizations may provide substandard care is that the organization is not liable for errors made by affiliated physicians; only the individual physician is liable.

These features of managed care may also make managed care less attractive to patients, especially to those most likely to incur large medical expenses. If plans have incentives to avoid serving sick patients, then sick patients have incentives to steer clear of these plans. Hence, one might expect the Medicaid caseload to change after the introduction of managed care, to the extent that patients are able to choose between Medicaid and other options. ${ }^{8}$

It is not clear a priori how increasing the degree of competition between MMC plans is likely to affect outcomes for those who remain enrolled in Medicaid. To the extent that patients who are dissatisfied with their plan have the option to switch plans without losing Medicaid services, competition may help to ensure that the package of services offered does not fall below some minimum level. On the other hand, in a single plan system, it may be more difficult to discourage high-cost patients from enrolling than in a system in which patients can be encouraged to move to another plan.

${ }^{8}$ Currie and Fahr (forthcoming) show for example, that black and Hispanic children were less likely to be enrolled in Medicaid following the introduction of MMC in California, which may reflect the fact that many were able to take advantage of a well-developed network of indigent care services instead. As discussed below, we find that black women were more likely to be enrolled, and Hispanic women less likely to be enrolled after the implementation of MMC, which seems less consistent with cream-skimming arguments (Hispanic babies tend to be healthier than other babies of similar socio-economic status) than with consumer preferences. 
And it is not certain that a public MMC plan run by the county would behave differently than a privately managed plan. There is a large literature on the differences between non-profit and for-profit organizations which highlights the fact that they may have somewhat different objectives; at the same time, both may be subject to similar market forces (c.f. Sloan, 2000). Given the complexity of the problem, it seems that only an empirical test can answer the questions of how the introduction of MMC affected patients, and whether mandating competition between MMC plans benefits patients.

\section{c) Previous Examinations of the Effects of Medicaid Managed Care}

Kaestner, Dubay, and Kenney (2002) provide an overview of the literature on the effects of MMC on the utilization of care and on health. They point out that most of the previous literature deals with effects on utilization of care rather than health outcomes, and that even the conclusions regarding utilization are mixed. Infants are the one group for whom there has been an attempt to link MMC to health outcomes, but the evidence here too is mixed, clouded by difficulties in controlling for potentially important unobserved characteristics of the women in MMC plans. ${ }^{9}$

${ }^{9}$ For example, Levinson and Ullman (1998) analyze a cross section from three Wisconsin counties and find that MMC increases both the utilization of prenatal care and birth weight compared to FFS. Moreno (1999) examined prenatal care and outcomes in Tennesee before and after the implementation of managed care, and find declines in some measures of prenatal care utilization, but there is no control group. Conover, Rankin and Sloan (2001) re-examine the impact of managed care in Tennessee using North Carolina as a control group and conclude that MMC may have reduced the utilization of high tech procedures without affecting outcomes. Other studies which suffer from similar limitations, and come to similarly mixed conclusions include Krieger et al. (1992), Goldfarb, Hillman, and Eisenberg (1991), Carey, Weis, and Homer (1991), Oleske, Brana and Schmidt (1998), and Griffin (1999). Sommers, Kenney and Dubay (2002) and Kenney, Sommers and Dubay (2003) use difference-in-difference methods to 
The study most closely related to the present work also examines the impact of MMC implementation on pregnant women in California. Baker, Schmitt, and Phibbs (2003) use Medicaid claims data to examine the impact of the introduction of MMC on utilization of care, costs, and outcomes. They therefore focus only on Medicaid mothers, and do not examine possible effects of MMC on the selection of mothers into Medicaid. This may be an important omission in view of evidence that women may decline to take up private health insurance coverage available through their employment in order to use Medicaid (Cutler and Gruber, 1996); and that many women eligible for Medicaid coverage of their pregnancies do not take up the coverage until relatively late in pregnancy (Ellwood and Kenney, 1995). It is also of interest to ask how MMC may have affected other low-income mothers. Baker et al. do not distinguish between types of MMC, and so do not ask whether the degree of competition makes a difference. However, the most important limitation of this study may be that they use the fraction of 15 to 44 year old Medi-Cal women who are in enrolled in managed care as the key independent variable measuring the effect of MMC. This variable includes women on Medi-Cal who were not pregnant (e.g. welfare recipients and the disabled), and does not adjust for the fact that many pregnant Medi-Cal recipients were not required to enroll in managed care, as discussed above. In Orange county in 2000, Baker et al. report that 75\% of Medi-Cal women 15-44 were in MMC; however, in the same year, only $27 \%$ of deliveries were in aid categories subject to MMC (Rains, 2000).

examine MMC in Missouri and Ohio respectively, while Kaestner, Dubay and Kenney (2002) examine a national sample drawn from the Vital Statistics Detail Natality files, and look at whether being in a county with a MMC plan affects birth outcomes. These three studies generally find little effect on birth outcomes, though the Ohio studies finds a positive impact on prenatal care. 
Given the growing share of Medi-Cal deliveries accounted for by undocumented women, the fraction of Medi-Cal deliveries subject to MMC often actually moves in the opposite direction to the fraction of all 15 to 44 year old Medi-Cal women subject to managed care. For example, Baker et al. show that in Alameda county, the fraction of 15 to 44 year old Medi-Cal women who were in managed care rose from 60 to 70 percent between 1998 and 2000. However, the fraction of Medi-Cal deliveries that were in aid categories subject to mandatory managed care in Alameda fell from 63\% to 48\% over the same two year interval (Rains, 2000).

Still, variations in both series after the implementation of MMC are smaller than the sharp jump that occurred when MMC was implemented, suggesting that the Baker et al. measure could capture large changes associated with the introduction of MMC. For example, if there are large changes in utilization but more subtle changes in outcomes, then the use of a noisy measure of MMC impact could capture changes in utilization but obscure changes in outcomes. In any case, Baker et al. conclude that the adoption of MMC did not reduce Medicaid spending, and may have increased it. They also find some differences in the utilization of health services after the adoption of MMC, including, for example, increases in access to high-level NICUs among low birth weight infants, and conclude that MMC may have improved outcomes among low birthweight infants.

Finally, in work in progress, Barham, Gertler, and Raube (2003) examine the impact of MMC in California using the California natality data. They do distinguish between COHS counties and Two-Plan counties, and attempt to control for unobserved characteristics of the MMC moms by using a difference-in-difference-in-differences design. In COHS counties, they compare the before/after MMC change in outcomes among Medi-Cal mothers to the change in 
outcomes among self-pay (uninsured) mothers. A problem with this procedure is that there are very few self-pay mothers over this time period. In Two-Plan counties, they compare the change in outcomes among Medi-Cal mothers to the change in outcomes among privately insured mothers.

However, if selection into MMCs is important, then neither the uninsured nor the privately insured are valid control groups, because the composition of these groups will be affected by a womans' decisions to enroll or not to enroll in Medi-Cal. Moreover, if the introduction of Two Plan or GMC systems affected health care for non-Medi-Cal women, then this will also invalidate the use of the non-Medi-Cal women as controls. In contrast, in our mother fixed effects design, each woman serves as her own control.

Our study design overcomes many of the limitations of previous work. By following the same mothers over time and examining changes in the enrollment patterns, utilization of care, and birth outcomes of mothers who became subject to different types of MMC, we will be better able to isolate the effects of these plans. By focusing on the population that was actually subject to MMC, we avoid drawing inferences about its effects from large numbers of women who were not required to enroll. And by merging data from several sources, we are able to examine a wide range of outcomes, and to judge whether the estimated effects are consistent across these outcomes.

\section{Data}

The main sources of information on birth outcomes are the California Birth Statistical Master File 1990-2000, and the Birth Cohort files for the same period. Both files have 
information about all of the births in California over the period, drawn from individual birth records. These files have maternal age, education, marital status, race/ethnicity, parity, county and zip code of residence, whether or not the delivery was paid for by Medicaid or a private payer, and a hospital code. In addition, they report outcomes including birth weight, as well as information about some procedures of labor and delivery. The Master file has confidential information including the mother's name and birth date, which has enabled us to link records for siblings, which allows us to estimate models with mother fixed effects. The Birth Cohort files link birth and death certificates. Hence, by using the common information about births in the Master files and the Birth Cohort files, we have created a longitudinal data base that has information about both births and deaths.

Information about the type of neo-natal intensive care unit (NICU) available in each hospital was generously supplied by Cairan Phibbs. In addition, we have generated hospitallevel information from the Vital Statistics records about the neo-natal infant mortality rate (i.e. deaths in the first 28 days divided by the number of births). We focus on neo-natal mortality as it is arguably more likely to be affected by hospital quality and the type of medical care received than infant mortality (death in the first year) which could reflect factors such as SIDS (Sudden Infant Death Syndrome) and accidental deaths. Since hospital-level mortality rates are likely to vary with the patient case-mix, we focus on "case-mix adjusted" neonatal mortality rates from residuals of regressions of the rates on maternal and child characteristics. ${ }^{10}$

\footnotetext{
${ }^{10}$ We estimate linear probability models for the probability of neonatal death controlling for the following maternal characteristics (all dummies): black, white, hispanic, asian, other race, teen mom, mom 20-29, mom 30-34, mom 35+, < high school, high school, some college, college or more, single, foreign-born, no pregnancy complications; the following child characteristics: first born, lbw, vlbw, twin, male, and the year. We then take the residuals from these regressions and aggregate them to the hospital level. This procedure identifies hospitals that were good or bad on average over the period,
} 
We start with data about 5,535,538 births. We dropped data from the 15 smallest counties, since these are very rural, and not at risk for managed care adoption. ${ }^{11}$ We also dropped multiple births, since these have a much higher incidence of negative outcomes, and differences in outcomes between multiples cannot be due to changes in the managed care environment.

The first two columns of Table 2a show sample statistics from a random 30 percent sample of this group of births in 1990, and 2000. The Table shows that about 40 percent of all deliveries in the state were covered by Medicaid, and this fraction was relatively constant over time. The data suggest some broad changes in the characteristics of hospitals delivering babies over time: There was a small increase in the fraction of infants born in hospitals with a NICU (neo-natal intensive care unit) of level 3 or higher, and the size of the average hospital where women delivered also fell appreciably. The increase in access to high-level NICUs might be expected to improve outcomes, while the shift away from large hospitals might in fact lead to a deterioration in infant health-while larger hospitals are not necessarily pleasant places to deliver, they are typically well equipped to handle emergencies and difficult cases, and there is a great deal of evidence that hospitals that perform more of any given medical procedure have better patient outcomes than those with smaller volumes.

Raw hospital-level neonatal death rates (i.e. deaths in the first month of life) decline from about 4.5 per 1,000 to 3.7 per 1,000. The comparison of the 1990 and 2000 caseload adjusted

so that we can interpret our estimates as the effect of shifting between hospitals of different average quality.

${ }^{11}$ We dropped Alpine, Amador, Calaveras, Colusa, Del Norte, Glenn, Inyo, Lassen, Mariposa, Modoc, Mono, Plumas, Sierra, Siskiyou, and Trinity counties. 
rates suggest that over time, births shifted to better hospitals, in terms of neonatal mortality rates. Note that we set rates for hospitals with fewer than 500 births per year to missing, in order to avoid unreliable rate calculations for small cells.

Turning to prenatal care, the state saw a large improvement in the fraction of women beginning prenatal care in the first trimester. This is an important indicator of the quality of prenatal care, and is also an indicator of the ease with which the newly pregnant women can get access to care. On the other hand, there was a large (relative to baseline) increase in the probability that an infant was transferred to another hospital after delivery. A higher rate of transfers can be regarded as a failure of prenatal care, since ideally, high risk infants should be identified before birth so that their mothers can be directed to hospitals with the necessary facilities. Infants who are transferred face a much higher risk of death than infants born into high tech hospitals to begin with.

Delivery care became more high-tech over time, with a doubling of the probability that labor was induced or stimulated, and a 37 percent increase in the use of fetal monitors. However, the use of Cesarian sections increased only 3.6 percent, perhaps because of efforts by hospitals and health insurers to monitor unnecessary use of this procedure. It is not clear whether these changes would be expected to lead to any improvement in average infant outcomes, because many of these procedures may be medically unnecessary, and conducted more for the convenience of the mother or doctor than for the benefit of the infant. However, more intensive care during delivery would be expected to be associated with higher costs. Consistent with other research, there was little state-wide trend in the incidence of low birth weight (defined as birth weight less than 2,500 grams), a widely used indicator of the health 
of the infant at birth. Nor is there much trend in the incidence of short gestation (gestation less than or equal to 258 days). This can be contrasted with the decline in the probability of neonatal death. The fact that the underlying health of infants delivered was stable, while the probability of death declined suggests that the decline was due to interventions at the time of delivery and in the first month. Thus, to the extent that the change to MMC affected the quality of hospital used, it could have a large impact on mortality.

The next two columns provide a comparison with our "analysis sample” of 255,000 births. This sample consists of all births to native-born, unmarried women with high school or less, who had two or more singleton births over our sample period. These women had a much higher than average probability of having a Medicaid delivery, although this probability fell by approximately 8 percentage points over time. Conversely, it is striking to note that even in this very disadvantaged group, 19 percent had private insurance for delivery, and that this proportion had increased to 27 percent by 2000 .

The data on hospital characteristics show that the analysis sample's probability of delivering in a hospital with an advanced NICU started much lower, but converged towards that of the whole sample. Our sample women also tended to deliver in somewhat smaller hospitals than average. The data on neonatal mortality rates indicate that sample women moved to hospitals with lower raw death rates over time, but at a slower rate than among other women.

It is striking that in contrast to the overall trends, the analysis sample showed a decrease in the incidence of low birth weight and short gestation over time. These means reflect the way that the sample is selected. For example, Table 2b, which shows means for the control variables that we include in our regressions, indicates that there are virtually no first born children in the 
analysis sample in 2000. This is because women had to have two or more children in order to be included. This criteria affects the rate of low birth weight and short gestation because first born children tend to be at higher risk. For similar reasons, in 2000 women in our analysis sample are older than the average mother, and much less likely to be teenage mothers. It is striking that neonatal mortality also falls, but much less than in the overall population.

The fifth column Table 2a shows the number of mothers experiencing a change in the outcome variable in question during the sample period. This information is important given that models that include mother fixed effects are identified by these changers. For all but very rare outcomes, such as transfers and deaths, there is a large sample with changes. The last column shows the mean change. If equal numbers experienced positive and negative changes in these largely dichotomous variables, then the mean would be zero. A positive number indicates that on average mothers moved from zero to one. These means indicate that for all our variables of interest, there are many changes in either direction.

Table $2 \mathrm{~b}$ indicates that the analysis sample is more likely to be African-American than the whole sample. The restriction to native-born mothers reduces the proportion of Hispanics slightly, though it is still 50 percent in 2000. The greatest effect of this restriction appears to be the elimination of most Asian mothers.

The last three columns of Table $2 \mathrm{~b}$ show changes in the characteristics of women delivering in the sample as a whole, over the 1990 to 2000 period, by whether the county eventually adopted COHS, Two-Plan/GMC, or no MMC. These columns suggest that the populations of women giving birth were evolving somewhat differently in the three types of counties. For example, the fraction of women who were black or Hispanic grew more rapidly in 
the Two-Plan/GMC counties than in the other types of counties, as did the fraction of mothers with less than a high school education, and the fraction of single mothers. Given these changes in the characteristics of mothers, we might expect outcomes to deteriorate in Two-Plan GMC counties relative to other counties. Thus, the Table illustrates the importance of controlling adequately for maternal characteristics when assessing the effect of MMC.

\section{Methods}

We estimate models of the following form:

(1) Outcome it $_{1}=\mathrm{b}_{0}+\mathrm{b}_{1} X_{\mathrm{it}}+\mathrm{b}_{2}$ year $_{\mathrm{t}}+\mathrm{b}_{3}$ COHS $_{\mathrm{t}}+\mathrm{b}_{4} 2$ Plan $/ G M C_{\mathrm{t}}+\mathrm{b}_{5}$ county_trend $\mathrm{t}+\mathrm{b}_{6} F E+e_{\mathrm{it}}$,

where Outcome is one of the variables listed in the first 5 panels of Table 2a, $X$ is the vector of maternal and child characteristics included in Table $2 \mathrm{~b}$, year is a vector of year dummies, and county_trend is a county-specific time trend which accounts for under-lying trends in the variables that we consider. Standard errors are clustered at the county-year level in order to account for factors that might affect all the observations in a particular county and year.

$F E$ refers to a vector of fixed effects, and we estimate two versions of (1) which include different types of fixed effects. The first model controls only for county level fixed effects. This model is in the same spirit as earlier work that has controlled for county fixed effects. The second model includes mother-specific fixed effects, which has not been done before. These models control for unobserved characteristics associated with the same mother, and identify the effects of MMC by using mothers who became subject to it between pregnancies. These models 
can be compared to those that control only for county fixed effects in order to guage the importance of controlling for unobserved characteristics of mothers.

In models of the form (1) we look at the effect of implementing MMC on the entire analysis sample of disadvantaged women. However, it is possible that the effects differ for those on Medi-Cal and those who are not. In particular, we may be concerned that MMC will cause reductions in the ability of safety net producers to serve uninsured women in Two Plan and GMC counties, as discussed above. Hence, we estimate a second set of models of the following form:

(2) Outcome $_{\mathrm{it}}=\mathrm{b}_{0}+\mathrm{b}_{1} X_{\mathrm{it}}+\mathrm{b}_{2}$ year $_{\mathrm{t}}+\mathrm{b}_{3}$ COHS $_{\mathrm{t}}+\mathrm{b}_{4} 2$ Plan $/ G M C_{\mathrm{t}}+\mathrm{b}_{5}$ MediCal $_{\mathrm{it}}+$

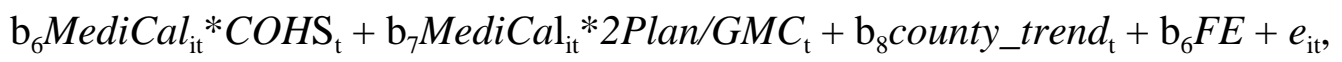
where the other variables are defined as above (except that we do not use insurance coverage as an outcome), and MediCal is whether or not the woman's delivery was covered by Medi-Cal.

Note that these fixed effects estimates are likely to be biased towards zero by random measurement error (caused, for example, by different nurses recording things more or less carefully, or by different hospital reporting practices). On the other hand, to the extent that measurement errors are associated with maternal reporting, and such reporting is constant over time, including fixed effects could help to deal with such errors and increase the precision of our estimates.

In addition to these basic models, we report the results of several specification checks. First, we re-estimate all of our models using less educated, native-born married women. While 
these women may be quite similar to our sample mothers in many respects, they are highly unlikely to be on welfare, and thus quite unlikely to be subject to MMC. As we show below, county MMC adoption had no impact on these mothers.

Secondly, mothers may experience a change in MMC either because they change counties, or because the law changed in the county that they were in. This observation raises the possibility that mobility between counties could be affected by the MMC environment. (Note that MMC status is determined by county of residence, not county of delivery, so we focus on county of residence). In order to deal with this possibility, we also estimate models in which we use the MMC environment the mother would have experienced had she remained in the county in which we first observe her, and ignore subsequent moves. While the county of the first (in our sample) birth is also a choice, factors influencing this choice can be controlled for via the inclusion of mother fixed effects. As we show below, this change also has no effect on our findings.

Thirdly, readers may be concerned that the estimated effects of MMC reflect a time trend of some kind, given that the MMC indicators turn “on” over time but generally do not turn “off”. We approach this problem in two ways. The first is to examine only counties that eventually adopted MMC, and adopt a "regression discontinuity design” in which we eliminate any births that occurred more than three years before adoption, or more than three years after adoption. In this design the effect of MMC is identified by changes between births that took place over a relatively short interval, so the estimated effects are unlikely to be driven by trends. While this reduces our sample size considerably, it generally strengthens our results as shown below.

Secondly, we added interactions between a time trend and indicators for whether the 
mother was black, hispanic, teen-aged, aged 20 to 29, aged 30 to 39, or had less than a high school education. If, for example, blacks were more likely than others to be subject to MMC, and the coefficient on "black" in the outcome equations was changing over time, then these trends would help to pick up any spurious correlation between MMC and outcomes that could result. However, since the results of this exercise produced estimates very similar to those shown below, we do not report them.

Finally, some readers may be concerned that the adoption of MMC was not really an exogenous event, since some counties took actions that were not in the original state plan. In particular, Napa and Monterey adopted COHS even though they were not mandated to do so. We have estimated alternative “intent-to-treat” models in which we assign MMC status on the basis of the state's planning document and ignore deviations. That is, we treat Napa and Monterey as though they never adopted COHS. Since Napa and Monterey are relatively small counties (as shown in Table 1) this has little impact on our estimates, and we do not report this specification below.

\section{Results}

a) Effects on Insurance Coverage

We begin the empirical analysis by asking whether the imposition of MMC had any effect on the probability that a woman was enrolled in Medi-Cal for the delivery. Note that very few women were uninsured at delivery during the 1990s, so if women did not have Medi-Cal, then they generally had private health insurance. One might expect that in our very disadvantaged population, the scope for leaving Medi-Cal and gaining private coverage would 
be rather small. Still, the estimated effects of MMC implementation on insurance coverage shown in Table 3 indicate that in 2Plan/GMC counties, women were 3 percent less likely to have Medicaid covered deliveries, and 3 percent more likely to have privately covered deliveries following the implementation of MMC. The results are virtually identical when mother fixed effects are included. Although Table 1 indicated that a sizeable fraction of these mothers did have private coverage, it is possible that these estimates are contaminated by reporting bias. For example, if the private MMC plan is Blue Cross, then perhaps women or providers identify the payor as a private plan rather than as Medi-Cal.

The second panel of Table 3 offers another look at the selection issue by asking whether the characteristics of mothers on Medi-Cal change after the implementation of MMC. Columns (1) and (2) show that Hispanic women became less likely to be covered by Medi-Cal following the introduction of MMC, especially in COHS counties, while black women became more likely to be covered in COHS counties. On average, black women tend to have poorer birth outcomes than similar whites, while Hispanic women tend to have better birth outcomes. On the whole then, the second half of Table 3 suggests that the Medi-Cal caseload became more negatively selected, in that the women covered by Medi-Cal after the implementation of MMC were more likely to have bad birth outcomes. Hence, these results emphasize the importance of adequately controlling for maternal characteristics when examining the effects of MMC. ${ }^{12}$

${ }^{12}$ We have estimated similar models for Medicaid coverage of prenatal care, and private coverage of prenatal care (since coverage of prenatal and delivery care are distinguished on the California birth certificate). The results were similar although slightly stronger for prenatal care than for deliveries. 
b) Effects on Prenatal Care, Hospital Quality, Delivery Care, and Outcomes

Table 4 explores the effect of MMC on prenatal care, hospital quality, delivery care and outcomes. Panel A shows county-fixed effects models, while mother-fixed effects models are shown in Panel B. In general, the addition of mother fixed effects reduces the estimated effects somewhat (an exception is fetal monitoring, where the Panel B coefficient for COHS counties greatly exceeds the equivalent coefficient in Panel A). In what follows, we will therefore focus on the mother fixed effects models.

Perhaps surprisingly, in view of the state's goals and the idea that managed care organizations promote preventive care, MMC implementation was associated with large decreases in the probability that disadvantaged women started prenatal care in the first trimester. The estimates suggest that this probability declined by 4 to 6 percentage points in both COHS and 2Plan/GMC counties. It is remarkable that the decline occurred against the backdrop of large overall increases in the early initiation of prenatal care as documented in Table 2a. COHS counties also experienced increases in the fraction of infants transferred, which remain marginally statistically significant $(\mathrm{t}=1.93)$ when mother fixed effects are added to the model.

The next three columns of Table 4 explore the effects of MMC on hospital quality. Column (3) shows an 11.2 percentage point increase in the probability that disadvantaged women in COHS counties delivered in a hospital with a high-level NICU, as well as a shifting of these women towards delivery in larger hospitals. It is interesting to contrast this result with that for transfers: If there is both an increase in the number of women going to hospitals with NICUs, and an increase in the number of infants being transferred in the COHS counties, then this suggests that the "wrong" women are going to the hospitals with NICUs, which is 
inefficient.

In 2Plan/GMC counties, there were no gains in NICU availability, and a smaller increase in the size of hospitals used for deliveries. Perhaps more importantly, in 2Plan/GMC counties disadvantaged women were shifted to hospitals with higher residual neonatal mortality rates, indicating hospitals of worse quality.

Columns (6) through (8) examine effects of MMC on delivery care. The estimates indicate that MMC had no effect on the probability of Cesarian delivery, but was associated with a shift towards higher-tech births in COHS counties: In these counties, the use of induction/stimulation of labor increased by 3.9 percentage points, and the use of fetal monitors increased by 11.9 percentage points following the introduction of MMC. In contrast, in 2Plan/GMC counties, there was a slight decline in the use of fetal monitors. As discussed above, it is not clear what implications these findings are likely to have for infant health, but the increased intensity of delivery services in COHS counties could well have increased costs. It is possible that these predominantly public-sector plans were under less pressure to cut costs than the private sector managed care organizations involved in the 2Plan/GMC counties. ${ }^{13}$

Finally, the last three columns of Table 4 indicate that the incidence of low birth weight, short gestation, and neonatal death all increased among Medi-Cal women following the introduction of MMC. Moreover, we cannot reject the null hypothesis that the effects were similar in COHS and 2Plan/GMC counties. Changes in the incidence of low birth weight and short gestation likely reflect inadequacies in prenatal care, while changes in the neonatal death

${ }^{13}$ Similarly, Duggan's (2000) work on the way that hospitals reacted to the incentives provided by the federal "disproportionate share" program suggests that public hospitals did not respond to these incentives while private hospitals did. 
rate reflect the effects of prenatal care as well as care that is received during and after the delivery. ${ }^{14}$

In summary, Table 4 shows that MMC implementation was associated with reductions in the quality of prenatal care. There were some potentially off-setting improvements in hospital quality in COHS counties, as well as an increase in high-tech delivery care to Medi-Cal mothers in these counties which is likely to have increased costs. However, infant health outcomes deteriorated in both COHS and 2Plan/GMC counties, to a roughly equal extent.

\section{c) Interacting Medi-Cal Delivery with MMC Implementation}

Table 5 shows estimates of model (2), in which Medi-Cal status is interacted with the dummy variables for MMC implementation. Table 2a showed that over $70 \%$ of our sample of disadvantaged women had Medi-Cal deliveries, so it may be difficult to separately identify effects on Medi-Cal and non-Medi-Cal women. However, it is interesting to ask whether MMC did actually have effects on non-Medi-Cal women in 2Plan/GMC counties, as its critics allege.

Table 5 indicates, for example, that in COHS counties, declines in the probability of beginning prenatal care in the first trimester were concentrated among Medi-Cal women, while in 2Plan/GMC counties, both Medi-Cal and non-Medi-Cal women experienced roughly equal declines. We interpret this finding as evidence that MMC did have a negative impact on nonMedi-Cal women in 2Plan/GMC counties. Presumably, this occurred in 2Plan/GMC counties

${ }^{14}$ There is some controversy about whether it is possible for prenatal care to affect the incidence of short gestation. On the one hand, until very recently, there were no known medical interventions that could affect the incidence of prematurity. On the other hand, factors such as infections, poor diet, and smoking are all thought to contribute to prematurity, so that holistic care that emphasized better health habits could have an impact. 
but not in COHS counties, because the traditional safety-net providers organized into the COHS plans were not harmed by a diversion of revenues to private Medi-Cal contractors.

However, an alternative, “difference-in-differences” interpretation would be that prenatal care declined among Medi-Cal women in COHS counties, but that in 2Plan/GMC counties, prenatal care use was declining among sample women for reasons unrelated to MMC. In this difference-in-difference framework, it would appear then, that COHS caused declines in prenatal care utilization, while 2Plan/GMC did not. We reject this alternative interpretation for several reasons: First, as discussed above, MMC may have affected non-Medi-Cal women in 2Plan/GMC counties; second, trends in prenatal care utilization were strongly positive, even in our disadvantaged sample, as shown in Table 2a; third, as we will show below, the introduction of MMC had no impact on less educated, married, native-born women in 2Plan/GMC counties, who were unlikely to be subject to it. Hence, it seems unlikely that we are confusing an underlying trend in prenatal care utilization in 2Plan/GMC counties with the effects of 2Plan/GMC utilization.

Table 5 indicates that in general the effects of MMC were the same for both Medi-Cal and non-Medi-Cal mothers in 2Plan/GMC counties. The one exception is for high-level NICUs, where the Medi-Cal mothers experience no significant change, while the non-Medi-Cal mothers experience a decline in access. In the COHS counties, it is somewhat easier to distinguish between Medi-Cal and other mothers. It is the Medi-Cal mothers in COHS counties who experience declines in prenatal care, increases in access to high-level NICUs, and increases in the use of fetal monitoring. They are, however, less likely than other mothers to shift to large hospitals which might offset the other gains in hospital quality. 
The last three columns of Table 5 indicate that these interactive models are not particularly informative about the effects of MMC on infant health outcomes, since the coefficients are not precisely estimated. However, the t-statistics shown at the bottom of the table indicate significant increases in low birth weight, short gestation, and neonatal death for Medi-Cal mothers in both COHS and 2Plan/GMC counties.

\section{d) Specification Checks}

Table 6 presents three sets of alternative estimates. Panel A shows estimates using married (rather than single) native-born less-educated women. These women have a much lower probability of being subject to MMC than the single women that we focus on. In the state as a whole in 2000, $65 \%$ of deliveries to native-born, less educated, single women were covered by Medi-Cal, while the comparable figure for similar married women was $28 \%$. Moreover, because married women are generally not eligible for welfare, the married women would have been much more likely to be in an aid category that was not subject to MMC. ${ }^{15}$ On the other hand, if our estimates were picking up a trend among less-educated women, then one would expect the trend to show up here also. Table 6 shows, however, that MMC had no effect on this sample of women. We have also estimated models for married, native-born women with more than a high school education, with similar results.

The second panel of Table 6 presents estimates in which the woman's MMC status is

${ }^{15}$ Recall that in 2000, $11.6 \%$ of Medi-Cal deliveries were not subject to MMC because the women were eligible due to low-income only. Births to married, less-educated, native-born women constituted only 3.4\% of the Medi-Cal caseload in 2000, so in principal, all of these women could have been in this non-MMC category. 
calculated using her initial county of residence only. As discussed above, these estimates are purged of any bias due to endogenous mobility, at the cost of introducing some measurement error in MMC status. The results are remarkably similar to those shown in Table 4, except that the COHS coefficient on induction/stimulation of labor becomes statistically insignificant, and the MMC coefficients in the models of short gestation and neonatal death are now significant at the $90 \%$ rather than the $95 \%$ level of confidence.

Panel C presents estimates based on births that occurred within plus or minus 3 years of MMC implementation. In these models, the MMC coefficients are identified using the sample of women who had one birth just prior to MMC implementation, and one birth just afterwards. Although the sample size is considerably reduced by this procedure, the estimates remain qualitatively similar, and in most cases the point estimates are larger-for example, the estimated effects of COHS on transfers gains in both size and statistical significance. Standard errors also increase, however, with the result that the estimated effects of COHS on infant outcomes are no longer statistically significant, although 2Plan/GMC is still estimated to increase low birth weight, short gestation, and neonatal death (the t-statistics are 1.83, 2.00, and 1.81, respectively), and we cannot reject the null hypothesis of equal coefficient estimates in the two types of counties.

Finally, as discussed above, we added interactions between a time trend and indicators for whether the mother was black, hispanic, teen-aged, aged 20 to 29, aged 30 to 39, or had less than a high school education. However, since the results of this exercise produced estimates 
very similar to those shown in Table 4 , we do not report them. ${ }^{16}$

\section{Discussion and Conclusions}

Our estimates suggest that the introduction of MMC was associated with increases in the incidence of low birth weight, short gestation, and neonatal death among the population of very disadvantaged women who were subject to the law. These deteriorations in infant health occurred despite a generally stable or improving picture in the state as a whole, and are quite robust to changes in specification.

Our estimates point to declines in access to prenatal care as a potential reason for the negative results. In COHS counties, the quality of hospitals where women delivered, and the intensity of delivery care increased, but apparently not enough to offset the other negative effects of MMC. In 2Plan/GMC counties, declines in access to prenatal care were reinforced by a shifting of disadvantaged women to hospitals of worse quality.

These results suggest that despite its well-documented failings, the old, competitive, feefor-service system with many atomistic providers of Medi-Cal services provided care that was better in many respects than either MMC system. Moreover, attempts to legislate competition by mandating the participation of two or more providers did not improve matters, indicating that some other method must be found to increase the quality of services rendered to Medicaid

${ }^{16}$ We also estimated models including interactions of mother and county fixed effects. These models are identified using mothers who stayed in the same county and experienced a change in MMC regime. The results were the same as those reported above with the important exception that the MMC variables were no longer jointly significant at the $90 \%$ level of confidence in the models for neonatal mortality. Since the point estimates are stable, we believe that this loss of statistical significance is a reflection of the smaller effective sample size, and the fact that neonatal mortality is a rare outcome. 
recipients in mandatory managed care plans. Finally, it is interesting to speculate on the extent to which these results might also apply to private managed care patients, who also often have little choice of health care provider. 


\section{References}

Arlen, Jennifer and W. Bentley MacLeod. "Malpractice Liability for Physicians and Managed Care Organizations,” New York University Law Review, 78 \#6, Dec. 2003, 1929-2006.

Baker, Laurence, Susan Schmitt and Ciaran Phibbs. "Medicaid Managed Care in California and Health Care for Newborns," Dept. of Health Research and Policy Stanford University, March 2003.

Barham, Tania, Paul Gertler, and Kristiana Raube. "Making Babies Healthier by Providing a Managed Care Option to California’s Poor," Hass School of Public Administration, Berkeley, June 2003.

Conover, C.J., P.J. Rankin and Frank Sloan. "Effects of Tennesee Medicaid Managed Care on Obstetrical Care and Birth Outcomes,” Journal of Health Politics, Policy and Law, 26 \#6, 2001, 1291-1324.

Coye, Molly Joel. Cover letter for "The Department of Health Services' Plan for Expanding Medi-Cal Managed Care,” (Sacramento CA: Department of Health Services), March 31, 1993.

A.J. and J.P. Newhouse (eds.) Handbook of Health Economics (Amsterdam: North Holland), 2000 .

Committee on Energy and Commerce House of Representatives. "Medicaid Managed Care in California: Hearing before the Subcommittee on Health and the Environment April 20, 1993," (Washington D.C.: U.S. Government Printing Office) ISBN 0-16-043412-2, 1994.

Currie, Janet and John Fahr. "Medicaid Managed Care: Effects on Children’s Medicaid Coverage and Utilization,” Journal of Public Economics, forthcoming.

Currie, Janet and Jon Gruber. "Saving Babies: The Efficacy and Cost of Recent Expansions of Medicaid Eligibility for Pregnant Women,” Journal of Political Economy, 104, Dec. 1996, 12631296.

Cutler, David and Jon Gruber. “Does Public Insurance Crowd Out Private Insurance?” The Quarterly Journal of Economics, 111 \#2, 1996, 391-430.

Duggan, Mark. "Hospital Ownership and Public Medical Spending," Quarterly Journal of Economics, CXI, November 2000, 1343-1374.

Glied, Sherri. "Managed Care," Handbook of Health Economics, A.J. Culyer and J.P. Newhouse (eds.) (Amsterdam: North Holland) volume 1A, 2000.

Griffin, J.F., J.W. Hogan, J.S. Buechner, and T.M. Leddy. “The Effect of a Medicaid Managed 
Care Program on the Adequacy of Prenatal Care Utilization in Rhode Island,” American Journal of Public Health, 89 \#4, 1999, 497-501.

Kaestner, Robert, Lisa Dubay and Genevieve Kenney. "Medicaid Managed Care and Infant Health: A National Evaluation,” (Cambridge MA: National Bureau of Economic Research) Working Paper \#8936, May 2002.

Kenney, Genevieve, Anna Sommers, and Lisa Dubay. "Moving to Mandatory Medicaid Managed Care in Ohio: Impacts for Pregnant Women and Infants," (Washington D.C.: The Urban Institute) April 10, 2003.

Klein, Jim. "Managed Care Annual Statistical Report," (Sacramento CA: California Dept. of Health Services Medical Care Statistics Section) various years.

Klein, Jim and Celine Donaldson. "Managed Care Annual Statistical Report,” (Sacramento CA: California Dept. of Healht Services Medical Care Statistics Section) March 2002.

Korenbrot, Carol, G. Miller, and J. Greene. "The Impact of Medicaid Managed Care on Community Clinics in Sacramento County, California,” American Journal of Public Health, 89 \#6, 1989, 913-917.

Krieger, J.W., F.A. Connell, and J.P. LoGerfo. "Medicaid Prenatal Care: A Comparison of Use and Outcomes in Fee-for-service and Managed Care,” American Journal of Public Health, 82 \#2, 1992, 185-190.

Levinson, A. and F. Ullman. "Medicaid Managed Care and Infant Health,” Journal of Health Economics, 17, 1998, 351-368.

Moreno, L. "The Influence of TennCare on Perinatal Outcomes. Perspectives on Medicaid Managed Care,” (Princeton NJ: Mathematica Policy Research) June 1999.

Oleske, D.M., M.L. Branca, J.B. Schmidt, R. Ferguson, and E.S. Linn. "A Comparison of Capitated and Fee-for-service Medicaid Reimbursement Methods on Pregnancy Outcomes," Health Services Research, 33 \#1, 1998, 55-73.

Sloan, Frank. "Not for profit Ownership and Hospital Behavior," Handbook of Health Economics, A.J. Culyer and J.P. Newhouse (eds.) (Amsterdam: North Holland) volume 1B, 2000.

Sommers, Anna, Genevieve Kenney and Lisa Dubay. "The Impact of Mandatory Medicaid Managed Care in Missouri: A Difference-in-Difference Approach,” (Washington D.C.: The Urban Institute) Dec. 15, 2002.

Tai-Seale, M. A.T. LoSasso, D.A. Freund, and S.E. Gerber. “The Long-term Effects of Medicaid 
Managed Care on Obstetric Care in Three California Counties,” Health Services Research, 36 \#4, 2001, 751-771. 
Table 1: The Adoption of Medicaid Managed Care

\begin{tabular}{|lccccc|}
\multicolumn{1}{c}{ County } & Type & $\begin{array}{c}\text { Date } \\
\text { Began }\end{array}$ & $\begin{array}{r}\text { 2000, Percent } \\
\text { Enrollment } \\
\text { Private Plan }\end{array}$ & \# births, 2000 & $\begin{array}{c}\text { Median HH } \\
\text { Income, 1999 }\end{array}$ \\
\hline Santa Barbara & COHS & Sep-83 & & 5601 & 46,677 \\
San Mateo & COHS & Dec-87 & & 10343 & 70,819 \\
Solano & COHS & May-94 & & 5831 & 54,099 \\
Orange & COHS & Oct-95 & & 46654 & 58,820 \\
Santa Cruz & COHS & Jan-96 & & 3382 & 53,998 \\
Napa & COHS & Mar-98 & & 1474 & 51,738 \\
Monterey & COHS & Oct-99 & & 6835 & 48,305 \\
Average for COHS: & & & 11,446 & 54,922 \\
\hline & & & & \\
Sacramento & GMC & Apr-94 & $100 \%$ & 17987 & 43,816 \\
Alameda & 2-Plan & Jan-96 & $27.80 \%$ & 21825 & 55,946 \\
San Joaquin & 2-Plan & Feb-96 & $19.60 \%$ & 9515 & 41,282 \\
Kern & 2-Plan & Jul-96 & $36.20 \%$ & 11542 & 35,446 \\
San Bernardino & 2-Plan & Sep-96 & $23.40 \%$ & 28329 & 42,066 \\
Riverside & 2-Plan & Sep-96 & $23.60 \%$ & 24633 & 42,887 \\
Santa Clara & 2-Plan & Oct-96 & $38.40 \%$ & 27388 & 74,335 \\
Fresno & 2-Plan & Nov-96 & $18.00 \%$ & 14141 & 34,725 \\
San Francisco & 2-Plan & Jul-96 & $39.00 \%$ & 8525 & 55,221 \\
Contra Costa & 2-Plan & Feb-97 & $11.20 \%$ & 13065 & 63,675 \\
Los Angeles & 2-Plan & Apr-97 & $39.90 \%$ & 156006 & 42,189 \\
Stanislaus & 2-Plan & Oct-97 & $42.00 \%$ & 7200 & 40,101 \\
San Diego & GMC & Jul-98 & $100 \%$ & 43759 & 47,067 \\
Tulare & 2-Plan & Feb-99 & $11.50 \%$ & 7194 & 33,983 \\
Average for 2Plan/GMC: & & & 27,936 & 46,624 \\
\hline & & & & \\
Avg. for 22 included counties that did not adopt: & & 1089 & 41,859 \\
\hline & & & 187 & 35,324 \\
\hline Avg. for 15 counties excluded from our sample: & & & \\
\hline
\end{tabular}

Notes: Counties that did not adopt, but are included in our sample include: Butte, El Dorado, Humboldt, Imperial, Kings, Lake, Madera, Marin, Mendocino, Merced, Nevada, Placer, San Benito San Luis Obispo, Shasta, Sonoma, Sutter, Tehema, Tuolumne, Ventura, Yuba \& Yolo. Yolo county implemented a managed care plan in 2001. Percent enrollments are for July 2000, except for Stanislaus county where the commercial plan ended in March 2000, so we use enrollments for July 1999.

Source: Klein and Donaldson, 2002 and authors' tabulations from Vital Statistics and 2000 U.S. Census. 
Table 2a: Mean Outcomes for All Births and for Analysis Sample

\begin{tabular}{|c|c|c|c|c|c|c|}
\hline Insurance Coverage & $\begin{array}{c}\text { All } \\
1990\end{array}$ & $\begin{array}{c}\text { All } \\
2000\end{array}$ & $\begin{array}{c}\text { Sample } \\
1990\end{array}$ & $\begin{array}{c}\text { Sample } \\
2000\end{array}$ & $\begin{array}{l}\text { \# Mothers } \\
\text { with any } \\
\text { Changes }\end{array}$ & $\begin{array}{l}\text { Mean } \\
\text { Change }\end{array}$ \\
\hline Medicaid for Delivery & 0.389 & 0.404 & 0.775 & 0.697 & 39131 & -0.064 \\
\hline Private Ins. for Delivery & 0.518 & 0.553 & 0.191 & 0.271 & 36370 & 0.097 \\
\hline \multicolumn{7}{|l|}{ Hospital Characteristics } \\
\hline$\overline{\text { Level } 3 \text { or higher NICU }}$ & 0.484 & 0.529 & 0.430 & 0.517 & 47260 & 0.077 \\
\hline \# Births & 3607 & 2867 & 3308 & 2724 & 198064 & -195 \\
\hline Neonatal Mort. Rate*100 & 0.449 & 0.372 & 0.458 & 0.413 & 196786 & -0.015 \\
\hline Adjusted NMR*100 & 0.009 & -0.005 & 0.001 & -0.006 & 89606 & -0.002 \\
\hline \multicolumn{7}{|l|}{ Prenatal Care } \\
\hline Began in 1st Trimester & 0.722 & 0.834 & 0.553 & 0.704 & 62714 & 0.051 \\
\hline InfantTransferred & 0.003 & 0.005 & 0.004 & 0.006 & 1845 & 0.107 \\
\hline \multicolumn{7}{|l|}{ Delivery Care } \\
\hline Induction/Stimulation Labor & 0.107 & 0.212 & 0.089 & 0.176 & 45768 & 0.035 \\
\hline Fetal Monitor & 0.488 & 0.668 & 0.458 & 0.644 & 60753 & 0.161 \\
\hline Cesarian & 0.221 & 0.229 & 0.201 & 0.211 & 23675 & 0.073 \\
\hline \multicolumn{7}{|l|}{ Infant Outcomes } \\
\hline Low Birth Weight & 0.052 & 0.055 & 0.078 & 0.061 & 18512 & -0.058 \\
\hline Gestation < 37 weeks & 0.095 & 0.097 & 0.135 & 0.127 & 31332 & 0.035 \\
\hline Neonatal Death*100 & 0.424 & 0.344 & 0.313 & 0.301 & 1222 & 0.026 \\
\hline Mother Chronic Condition & 0.024 & 0.032 & 0.015 & 0.025 & 6090 & 0.178 \\
\hline
\end{tabular}

Notes: "All" is a 30\% sample of singleton births excluding the 15 counties with the fewest births in 2000 The analysis sample is all native born mothers with $>=2$ births in the sample, who had $<=$ highschool, \& who were unmarried at each point at which they were observed. 
Table 2b: Means of Mother/Child Characteristics for Full Sample, and Analysis Sample

\begin{tabular}{|c|c|c|c|c|c|c|c|}
\hline & $\begin{array}{c}\text { All } \\
1990\end{array}$ & $\begin{array}{c}\text { All } \\
2000\end{array}$ & $\begin{array}{c}\text { Sample } \\
1990\end{array}$ & $\begin{array}{c}\text { Sample } \\
2000\end{array}$ & $\begin{array}{c}\text { All } \\
\text { 1990-2000 } \\
\text { Change in } \\
\text { COHS }\end{array}$ & $\begin{array}{c}\text { All } \\
\text { 1990-2000 } \\
\text { Change in } \\
\text { 2Plan/GMC }\end{array}$ & $\begin{array}{c}\text { All } \\
\text { 1990-2000 } \\
\text { Change in } \\
\text { No MMC }\end{array}$ \\
\hline Black & 0.079 & 0.065 & 0.296 & 0.237 & 0.017 & 0.044 & 0.009 \\
\hline White & 0.416 & 0.321 & 0.321 & 0.241 & 0.061 & 0.027 & 0.066 \\
\hline Hispanic & 0.408 & 0.490 & 0.367 & 0.500 & -0.024 & -0.016 & -0.064 \\
\hline Asian & 0.060 & 0.081 & 0.002 & 0.006 & -0.037 & -0.040 & -0.006 \\
\hline Mother < High School & 0.339 & 0.297 & 0.530 & 0.409 & 0.101 & 0.145 & 0.105 \\
\hline Mother High School & 0.313 & 0.287 & 0.470 & 0.591 & 0.061 & 0.043 & 0.056 \\
\hline Mother Some College & 0.195 & 0.200 & 0 & 0 & -0.041 & -0.076 & -0.058 \\
\hline Foreign Born & 0.413 & 0.456 & 0 & 0 & -0.045 & -0.024 & -0.041 \\
\hline Mother Single & 0.304 & 0.324 & 1 & 1 & 0.159 & 0.223 & 0.157 \\
\hline Teen Mother & 0.114 & 0.105 & 0.417 & 0.123 & 0.042 & 0.060 & 0.043 \\
\hline Mother 20-29 & 0.561 & 0.494 & 0.511 & 0.716 & 0.105 & 0.062 & 0.057 \\
\hline Mother 30-34 & 0.219 & 0.241 & 0.060 & 0.112 & -0.062 & -0.053 & -0.037 \\
\hline Child First Born & 0.401 & 0.386 & 0.461 & 0.002 & 0.038 & 0.012 & 0.008 \\
\hline Child Male & 0.513 & 0.512 & 0.511 & 0.512 & -0.001 & 0.002 & -0.002 \\
\hline \#Obs & 175564 & 155112 & 25945 & 17762 & & & \\
\hline
\end{tabular}

See Table 2a notes. 
Table 3: Effect of MMC on Enrollments in Medi-Cal/Private Insurance

$\begin{array}{lcccc} & \begin{array}{c}{[\mathbf{1}]} \\ \text { MediCal } \\ \text { Delivery } \\ \text { yes }\end{array} & \begin{array}{c}{[\mathbf{2}]} \\ \text { MediCal } \\ \text { Delivery } \\ \text { no }\end{array} & \begin{array}{c}{[3]} \\ \text { Private } \\ \text { Delivery } \\ \text { yes }\end{array} & \begin{array}{c}{[4]} \\ \text { Private } \\ \text { Delivery } \\ \text { no }\end{array} \\ \begin{array}{l}\text { Mother FE } \\ \text { Panel A }\end{array} & \text { no } & \text { yes } & \text { no } & \text { yes } \\ \text { COHS } & -0.026 & -0.01 & 0.015 & 0.017 \\ & {[0.017]} & {[0.023]} & {[0.019]} & {[0.021]} \\ \text { 2Plan/GMC } & -0.027 & -0.025 & 0.026 & 0.023 \\ & {[0.006]^{* *}} & {[0.006]^{* *}} & {[0.006]^{* *}} & {[0.006]^{* *}} \\ \text { \#Obs. } & 255018 & 255018 & 255018 & 255018 \\ \text { R-squared } & 0.060 & 0.7 & 0.070 & 0.71 \\ & & & & \\ \text { Test COHS=2Plan/ } & 10.21 & 8.06 & 11.27 & 7.21 \\ \quad \text { GMC=0 } & 0.000 & 0.000 & 0.000 & 0.001 \\ \text { Test COHS=2Plan/GMC } & 0.01 & 0.44 & 0.34 & 0.07 \\ & 0.034 & 0.506 & 0.558 & 0.785\end{array}$

Panel B: Mother Fixed Effects Models of Prob(Medi-Cal Delivery)

Include Interactions of Indicated Maternal Characteristics with MMC

Characteristic:

COHS*Characteristic

2Plan/GMC*

Characteristic

COHS

2Plan/GMC

Main Effect

Characteristic

\#Obs.

R-squared

$\begin{array}{ccc}\text { Chronic } & \text { Hispanic } & \text { Black } \\ 0.03 & -0.065 & 0.048 \\ {[0.032]} & {[0.022]^{* *}} & {[0.023]^{*}} \\ -0.003 & -0.024 & 0.011 \\ {[0.020]} & {[0.008]^{* *}} & {[0.008]} \\ -0.011 & 0.022 & -0.016 \\ {[0.023]} & {[0.026]} & {[0.021]} \\ -0.025 & -0.015 & -0.028 \\ {[0.006]^{* *}} & {[0.007]^{*}} & {[0.007]^{* *}} \\ -0.023 & 0.004 & 0.012 \\ {[0.009]^{* *}} & {[0.013]} & {[.017]} \\ 255076 & 255018 & 255018 \\ 0.7 & 0.7 & 0.7\end{array}$

Notes: Robust standard errors in brackets are clustered at county-year level. P-values for F-statistics in italics. Panel A regressions included all of the mother and child characteristics in Table 2, except chronic conditions. All regressions also included year fixed effects and county-specific time trends. Regressions without mother fixed effects include county fixed effects. 
Table 4: Effects of MMC on Prenatal Care, Hospital Quality, Delivery Care and Outcomes

\begin{tabular}{|c|c|c|c|c|c|c|c|c|c|c|c|}
\hline & $\begin{array}{c}\text { [1] } \\
\text { Prenatal } \\
\text { 1st tri. }\end{array}$ & $\begin{array}{c}\text { [2] } \\
\text { Infant } \\
\text { Transfer }\end{array}$ & NICU & $\begin{array}{c}\text { [4] } \\
\text { Log } \\
\text { Births }\end{array}$ & $\begin{array}{c}\text { [5] } \\
\text { Residual } \\
\text { NMR }\end{array}$ & $\begin{array}{c}\text { [6] } \\
\text { Induction } \\
\text { Stim.Labor }\end{array}$ & $\begin{array}{c}\text { [7] } \\
\text { Fetal } \\
\text { Monitor }\end{array}$ & $\begin{array}{c}\text { [8] } \\
\text { Cesarian }\end{array}$ & $\begin{array}{c}\text { [9] } \\
\text { Low Birth } \\
\text { Weight }\end{array}$ & $\begin{array}{c}\text { [10] } \\
\text { Short } \\
\text { Gestation }\end{array}$ & $\begin{array}{c}\text { [11] } \\
\text { Neonatal } \\
\text { Death }\end{array}$ \\
\hline \multicolumn{12}{|c|}{ Panel A: County Fixed Effects Models } \\
\hline \multirow[t]{2}{*}{ COHS } & -0.075 & 0.427 & 0.103 & 0.086 & 0.151 & -0.006 & 0.016 & 0.019 & 0.022 & 0.022 & 0.295 \\
\hline & {$[0.021]^{* *}$} & {$[0.214]^{*}$} & {$[0.047]^{*}$} & {$[0.029]^{* *}$} & {$[0.096]$} & [0.011] & [0.029] & {$[0.012]$} & {$[0.009]^{*}$} & {$[0.012]$} & {$[0.206]$} \\
\hline \multirow[t]{2}{*}{ 2Plan/GMC } & -0.078 & 0.055 & 0.005 & 0.055 & 0.1 & -0.002 & -0.025 & -0.006 & 0.024 & 0.024 & 0.19 \\
\hline & {$[0.012]^{* *}$} & {$[0.064]$} & {$[0.010]$} & {$[0.011]^{* *}$} & {$[0.040]^{*}$} & {$[0.007]$} & {$[0.012]^{*}$} & [0.003] & {$[0.003]^{* *}$} & {$[0.006]^{* *}$} & {$[0.056]^{* *}$} \\
\hline Observations & 255018 & 255018 & 255018 & 254953 & 248438 & 255018 & 255018 & 255018 & 255007 & 242314 & 255018 \\
\hline R-squared & 0.04 & 0 & 0.19 & 0.25 & 0.08 & 0.06 & 0.14 & 0.01 & 0.01 & 0.01 & 0 \\
\hline \multirow{2}{*}{$\begin{array}{l}\text { Test } \mathrm{COHS}= \\
\text { 2Plan/GMC=0 }\end{array}$} & 26.29 & 2.39 & 2.74 & 16.85 & 4.29 & 0.17 & 2.13 & 2.98 & 44.92 & 8.29 & 6.34 \\
\hline & 0.000 & 0.092 & 0.065 & 0.000 & 0.014 & 0.842 & 0.112 & 0.051 & 0.000 & 0.000 & 0.002 \\
\hline \multirow{2}{*}{$\begin{array}{l}\text { Test COHS= } \\
2 \text { Plan/GMC }\end{array}$} & 0.02 & 2.75 & 4.01 & 1.03 & 0.25 & 0.08 & 1.62 & 3.82 & 0.02 & 0.01 & 0.25 \\
\hline & 0.891 & 0.097 & 0.045 & 0.310 & 0.618 & 0.782 & 0.203 & 0.051 & 0.880 & 0.918 & 0.616 \\
\hline \multicolumn{12}{|c|}{ Panel B: Mother Fixed Effects Models } \\
\hline \multirow[t]{2}{*}{ COHS } & -0.058 & 0.327 & 0.112 & 0.094 & 0.088 & 0.039 & 0.119 & -0.003 & 0.014 & 0.025 & 0.308 \\
\hline & {$[0.019]^{* *}$} & [0.169] & {$[0.032]^{* *}$} & {$[0.016]^{* *}$} & {$[0.095]$} & {$[0.017]^{*}$} & {$[0.037]^{* *}$} & {$[0.008]$} & {$[0.007]^{*}$} & {$[0.012]^{*}$} & {$[0.160]$} \\
\hline \multirow[t]{2}{*}{ 2Plan/GMC } & -0.044 & 0.005 & 0.005 & 0.022 & 0.082 & 0.002 & -0.023 & 0.001 & 0.013 & 0.015 & 0.160 \\
\hline & {$[0.008]^{* *}$} & [0.090] & [0.009] & [0.012] & {$[0.034]^{*}$} & {$[0.007]$} & {$[0.009]^{*}$} & [0.003] & {$[0.003]^{* *}$} & {$[0.007]^{*}$} & {$[0.070]^{*}$} \\
\hline Observations & 255018 & 255018 & 255018 & 254953 & 248438 & 255018 & 255018 & 255018 & 255007 & 242314 & 255018 \\
\hline R-squared & 0.6 & 0.52 & 0.76 & 0.79 & 0.72 & 0.6 & 0.69 & 0.82 & 0.61 & 0.59 & 0.54 \\
\hline Test COHS= & 15.52 & 1.97 & 7.02 & 17.3 & 3.12 & 2.73 & 7.68 & 0.19 & 12.11 & 3.74 & 3.65 \\
\hline 2Plan/GMC $=0$ & 0.000 & 0.139 & 0.001 & 0.000 & 0.044 & 0.065 & 0.001 & 0.829 & 0.000 & 0.024 & 0.026 \\
\hline Test COHS= & 0.58 & 3.59 & 9.64 & 18.79 & 0.00 & 4.55 & 13.36 & 0.31 & 0.02 & 0.73 & 0.86 \\
\hline 2Plan/GMC & 0.448 & 0.058 & 0.002 & 0.000 & 0.948 & 0.033 & 0.000 & 0.577 & 0.876 & 0.394 & 0.354 \\
\hline
\end{tabular}

Notes: Robust standard errors in brackets are clustered at the county-year level. P-values for F-tests in italics. All regressions also include indicators for maternal race and ethnicity, maternal education, mother age, whether the child was first born, and whether the child was male as well as year dummies and county-specific time trends. Coefficients and standard errors on hospital death rates are multiplied by 1,000. Coefficients and standard errors on transfers and neonatal death are multiplied by 100 . 
Table 5: Effects of MMC Interacted with Medi-Cal Delivery, Mother Fixed Effects Models

\begin{tabular}{|c|c|c|c|c|c|c|c|c|c|c|c|}
\hline & $\begin{array}{c}\text { [1] } \\
\text { Prenatal } \\
\text { 1st tri. }\end{array}$ & $\begin{array}{c}\text { [2] } \\
\text { Infant } \\
\text { Transfer }\end{array}$ & NICU & $\begin{array}{c}\text { [4] } \\
\text { Log } \\
\text { Births }\end{array}$ & $\begin{array}{c}\text { [5] } \\
\text { Residual } \\
\text { NMR }\end{array}$ & $\begin{array}{c}\quad[6] \\
\text { Induction } \\
\text { Stim.Labor }\end{array}$ & $\begin{array}{c}\text { [7] } \\
\text { Fetal } \\
\text { Monitor }\end{array}$ & $\begin{array}{c}{[8]} \\
\text { Cesarian }\end{array}$ & $\begin{array}{c}{[9]} \\
\text { Low Birth } \\
\text { Weight }\end{array}$ & $\begin{array}{c}\text { [10] } \\
\text { Short } \\
\text { Gestation }\end{array}$ & $\begin{array}{c}{[11]} \\
\text { Neonatal } \\
\text { Death }\end{array}$ \\
\hline COHS & $\begin{array}{c}-0.029 \\
{[0.021]}\end{array}$ & $\begin{array}{c}-0.02 \\
{[0.272]}\end{array}$ & $\begin{array}{c}0.058 \\
{[0.042]}\end{array}$ & $\begin{array}{c}0.144 \\
{[0.029]^{* *}}\end{array}$ & $\begin{array}{c}0.036 \\
{[0.104]}\end{array}$ & $\begin{array}{c}0.038 \\
{[0.023]}\end{array}$ & $\begin{array}{c}0.049 \\
{[0.031]}\end{array}$ & $\begin{array}{l}-0.003 \\
{[0.010]}\end{array}$ & $\begin{array}{c}0.006 \\
{[0.008]}\end{array}$ & $\begin{array}{c}0.024 \\
{[0.014]}\end{array}$ & $\begin{array}{c}0.258 \\
{[0.172]}\end{array}$ \\
\hline $\begin{array}{l}\text { COHS } \\
* \text { MediCal }\end{array}$ & $\begin{array}{c}-0.046 \\
{[0.020]^{*}}\end{array}$ & $\begin{array}{c}0.529 \\
{[0.276]}\end{array}$ & $\begin{array}{c}0.081 \\
{[0.026]^{* *}}\end{array}$ & $\begin{array}{c}-0.076 \\
{[0.033]^{*}}\end{array}$ & $\begin{array}{c}0.106 \\
{[0.172]}\end{array}$ & $\begin{array}{c}0.001 \\
{[0.022]}\end{array}$ & $\begin{array}{c}0.108 \\
{[0.038]^{* *}}\end{array}$ & $\begin{array}{c}0 \\
{[0.010]}\end{array}$ & $\begin{array}{c}0.012 \\
{[0.008]}\end{array}$ & $\begin{array}{c}0.003 \\
{[0.012]}\end{array}$ & $\begin{array}{c}0.071 \\
{[0.162]}\end{array}$ \\
\hline 2Plan/GMC & $\begin{array}{c}-0.049 \\
{[0.012]^{* *}}\end{array}$ & $\begin{array}{c}-0.034 \\
{[0.104]}\end{array}$ & $\begin{array}{c}-0.039 \\
{[0.014]^{* *}}\end{array}$ & $\begin{array}{c}0.05 \\
{[0.019]^{* *}}\end{array}$ & $\begin{array}{c}0.015 \\
{[0.051]}\end{array}$ & $\begin{array}{c}0.006 \\
{[0.009]}\end{array}$ & $\begin{array}{c}-0.003 \\
{[0.013]}\end{array}$ & $\begin{array}{c}-0.001 \\
{[0.004]}\end{array}$ & $\begin{array}{c}0.009 \\
{[0.004]^{*}}\end{array}$ & $\begin{array}{c}0.012 \\
{[0.009]}\end{array}$ & $\begin{array}{c}0.043 \\
{[0.110]}\end{array}$ \\
\hline $\begin{array}{r}\text { 2Plan/GMC } \\
* \text { MediCal }\end{array}$ & $\begin{array}{c}0.006 \\
{[0.010]}\end{array}$ & $\begin{array}{c}0.05 \\
{[0.099]}\end{array}$ & $\begin{array}{c}0.055 \\
{[0.015]^{* *}}\end{array}$ & $\begin{array}{l}-0.037 \\
{[0.020]}\end{array}$ & $\begin{array}{c}0.075 \\
{[0.057]}\end{array}$ & $\begin{array}{l}-0.006 \\
{[0.009]}\end{array}$ & $\begin{array}{l}-0.027 \\
{[0.014]}\end{array}$ & $\begin{array}{c}0.003 \\
{[0.004]}\end{array}$ & $\begin{array}{c}0.005 \\
{[0.004]}\end{array}$ & $\begin{array}{c}0.004 \\
{[0.007]}\end{array}$ & $\begin{array}{c}0.151 \\
{[0.107]}\end{array}$ \\
\hline MediCal delivery & $\begin{array}{c}-0.031 \\
{[0.005]^{* *}}\end{array}$ & $\begin{array}{c}-0.008 \\
{[0.063]}\end{array}$ & $\begin{array}{c}-0.065 \\
{[0.011]^{* *}}\end{array}$ & $\begin{array}{c}-0.011 \\
{[0.014]}\end{array}$ & $\begin{array}{c}-0.024 \\
{[0.042]}\end{array}$ & $\begin{array}{c}-0.003 \\
{[0.005]}\end{array}$ & $\begin{array}{c}-0.033 \\
{[0.011]^{* *}}\end{array}$ & $\begin{array}{c}0.006 \\
{[0.002]^{*}}\end{array}$ & $\begin{array}{c}-0.004 \\
{[0.002]}\end{array}$ & $\begin{array}{c}-0.006 \\
{[0.003]}\end{array}$ & $\begin{array}{c}-0.077 \\
{[0.051]}\end{array}$ \\
\hline $\begin{array}{l}\text { Observations } \\
\text { R-squared }\end{array}$ & $\begin{array}{c}255018 \\
0.61\end{array}$ & $\begin{array}{c}255018 \\
0.52\end{array}$ & $\begin{array}{c}255018 \\
0.76\end{array}$ & $\begin{array}{c}254953 \\
0.79\end{array}$ & $\begin{array}{c}254953 \\
0.72\end{array}$ & $\begin{array}{c}255018 \\
0.6\end{array}$ & $\begin{array}{c}255018 \\
0.69\end{array}$ & $\begin{array}{c}255018 \\
0.82\end{array}$ & $\begin{array}{c}255007 \\
0.61\end{array}$ & $\begin{array}{c}242314 \\
0.59\end{array}$ & $\begin{array}{c}255018 \\
0.54\end{array}$ \\
\hline $\begin{array}{l}\text { Test Sum COHS } \\
\text { terms }=0\end{array}$ & $\begin{array}{l}13.89 \\
0.000\end{array}$ & $\begin{array}{c}8.43 \\
0.004\end{array}$ & $\begin{array}{l}22.84 \\
0.000\end{array}$ & $\begin{array}{l}13.80 \\
0.000\end{array}$ & $\begin{array}{c}1.12 \\
0.290\end{array}$ & $\begin{array}{r}5.18 \\
0.023\end{array}$ & $\begin{array}{l}12.37 \\
0.000\end{array}$ & $\begin{array}{c}0.16 \\
0.689\end{array}$ & $\begin{array}{c}5.17 \\
0.023\end{array}$ & $\begin{array}{c}4.29 \\
0.038\end{array}$ & $\begin{array}{c}3.33 \\
0.068\end{array}$ \\
\hline $\begin{array}{l}\text { Test Sum 2Plan/GMC } \\
\text { terms }=0\end{array}$ & $\begin{array}{l}24.81 \\
0.000\end{array}$ & $\begin{array}{c}0.03 \\
0.867\end{array}$ & $\begin{array}{c}2.58 \\
0.109\end{array}$ & $\begin{array}{c}1.00 \\
0.318\end{array}$ & $\begin{array}{c}5.49 \\
0.019\end{array}$ & $\begin{array}{c}0.00 \\
0.977\end{array}$ & $\begin{array}{c}8.22 \\
0.004\end{array}$ & $\begin{array}{r}0.33 \\
0.565\end{array}$ & $\begin{array}{l}22.55 \\
0.000\end{array}$ & $\begin{array}{c}5.02 \\
0.025\end{array}$ & $\begin{array}{c}6.97 \\
0.008\end{array}$ \\
\hline $\begin{array}{l}\text { Test all MMC } \\
\text { terms }=0\end{array}$ & $\begin{array}{c}9.28 \\
0.000\end{array}$ & $\begin{array}{r}2.48 \\
0.042\end{array}$ & $\begin{array}{l}12.37 \\
0.000\end{array}$ & $\begin{array}{c}9.01 \\
0.000\end{array}$ & $\begin{array}{r}1.73 \\
0.141\end{array}$ & $\begin{array}{r}1.46 \\
0.213\end{array}$ & $\begin{array}{r}5.15 \\
0.001\end{array}$ & $\begin{array}{c}0.17 \\
0.952\end{array}$ & $\begin{array}{r}6.35 \\
0.000\end{array}$ & $\begin{array}{c}1.94 \\
0.100\end{array}$ & $\begin{array}{c}2.34 \\
0.052\end{array}$ \\
\hline
\end{tabular}

Notes: See Table 4 notes. 
Table 6: Specification Checks (Mother Fixed Effects Models)

\begin{tabular}{|c|c|c|c|c|c|c|c|c|c|c|c|c|}
\hline & $\begin{array}{l}\quad[1] \\
\text { Medi-Cal } \\
\text { Delivery }\end{array}$ & $\begin{array}{c}\text { [2] } \\
\text { Prenatal } \\
\text { 1st tri. }\end{array}$ & $\begin{array}{c}\text { [3] } \\
\text { Infant } \\
\text { Transfer }\end{array}$ & $\begin{array}{c}{[4]} \\
\text { NICU }\end{array}$ & $\begin{array}{c}\text { [5] } \\
\text { Log } \\
\text { Births }\end{array}$ & $\begin{array}{c}\text { [6] } \\
\text { Residual } \\
\text { NMR }\end{array}$ & $\begin{array}{c}{[7]} \\
\text { Induction } \\
\text { Stim.Labor }\end{array}$ & $\begin{array}{c}{[8]} \\
\text { Fetal } \\
\text { Monitor }\end{array}$ & $\begin{array}{c}\text { [9] } \\
\text { Cesarian }\end{array}$ & $\begin{array}{c}{[10]} \\
\text { Low Birth } \\
\text { Weight }\end{array}$ & $\begin{array}{c}\text { [11] } \\
\text { Short } \\
\text { Gestation }\end{array}$ & $\begin{array}{c}{[12]} \\
\text { Neonatal } \\
\text { Death }\end{array}$ \\
\hline \multicolumn{13}{|c|}{ Panel A: Married Native-Born Mothers with Highschool or Less } \\
\hline COHS & $\begin{array}{c}-0.001 \\
{[0.036]}\end{array}$ & $\begin{array}{c}-0.046 \\
{[0.037]}\end{array}$ & $\begin{array}{c}-0.102 \\
{[0.730]}\end{array}$ & $\begin{array}{c}0.026 \\
{[0.060]}\end{array}$ & $\begin{array}{c}0.086 \\
{[0.073]}\end{array}$ & $\begin{array}{c}0.052 \\
{[0.127]}\end{array}$ & $\begin{array}{c}0.045 \\
{[0.064]}\end{array}$ & $\begin{array}{c}0.082 \\
{[0.060]}\end{array}$ & $\begin{array}{c}-0.019 \\
{[0.028]}\end{array}$ & $\begin{array}{c}0.002 \\
{[0.020]}\end{array}$ & $\begin{array}{c}0.005 \\
{[0.025]}\end{array}$ & $\begin{array}{c}0.118 \\
{[0.405]}\end{array}$ \\
\hline 2Plan/GMC & $\begin{array}{c}-0.008 \\
{[0.022]}\end{array}$ & $\begin{array}{c}-0.032 \\
{[0.025]}\end{array}$ & $\begin{array}{c}0.174 \\
{[0.515]}\end{array}$ & $\begin{array}{c}-0.037 \\
{[0.033]}\end{array}$ & $\begin{array}{c}0.003 \\
{[0.035]}\end{array}$ & $\begin{array}{c}0.027 \\
{[0.123]}\end{array}$ & $\begin{array}{c}-0.003 \\
{[0.029]}\end{array}$ & $\begin{array}{c}-0.016 \\
{[0.030]}\end{array}$ & $\begin{array}{c}0.009 \\
{[0.016]}\end{array}$ & $\begin{array}{c}0.005 \\
{[0.014]}\end{array}$ & $\begin{array}{c}-0.007 \\
{[0.023]}\end{array}$ & $\begin{array}{c}0.441 \\
{[0.319]}\end{array}$ \\
\hline \#Obs. & 134023 & 134023 & 134023 & 134023 & 133998 & 128890 & 134023 & 134023 & 134023 & 134015 & 129032 & 134023 \\
\hline R-squared & 0.96 & 0.91 & 0.92 & 0.95 & 0.95 & 0.94 & 0.9 & 0.93 & 0.96 & 0.92 & 0.91 & 0.9 \\
\hline $\begin{array}{l}\text { Test COHS=2Plan } / \\
\text { GMC }=0\end{array}$ & $\begin{array}{c}0.06 \\
0.938\end{array}$ & $\begin{array}{c}1.24 \\
0.290\end{array}$ & $\begin{array}{c}0.10 \\
0.909\end{array}$ & $\begin{array}{c}0.87 \\
0.421\end{array}$ & $\begin{array}{c}0.70 \\
0.498\end{array}$ & $\begin{array}{c}0.09 \\
0.911\end{array}$ & $\begin{array}{c}0.27 \\
0.767\end{array}$ & $\begin{array}{c}1.27 \\
0.280\end{array}$ & $\begin{array}{c}0.47 \\
0.626\end{array}$ & $\begin{array}{r}0.06 \\
0.944\end{array}$ & $\begin{array}{c}0.09 \\
0.913\end{array}$ & $\begin{array}{c}1.01 \\
0.365\end{array}$ \\
\hline \multicolumn{13}{|c|}{ Panel B: MMC Classification Based on Initial County Only } \\
\hline COHS & $\begin{array}{c}-0.015 \\
{[0.022]}\end{array}$ & $\begin{array}{c}-0.059 \\
{[0.018]^{* *}}\end{array}$ & $\begin{array}{c}0.205 \\
{[0.179]}\end{array}$ & $\begin{array}{c}0.103 \\
{[0.029]^{* *}}\end{array}$ & $\begin{array}{c}0.080 \\
{[0.015]^{* *}}\end{array}$ & $\begin{array}{c}0.108 \\
{[0.086]}\end{array}$ & $\begin{array}{c}0.024 \\
{[0.016]}\end{array}$ & $\begin{array}{c}0.096 \\
{[0.029]^{* *}}\end{array}$ & $\begin{array}{c}0.000 \\
{[0.007]}\end{array}$ & $\begin{array}{c}0.014 \\
{[0.006]^{*}}\end{array}$ & $\begin{array}{c}0.017 \\
{[0.010]}\end{array}$ & $\begin{array}{c}0.258 \\
{[0.151]}\end{array}$ \\
\hline 2Plan/GMC & $\begin{array}{c}-0.026 \\
{[0.006]^{* *}}\end{array}$ & $\begin{array}{c}-0.044 \\
{[0.008]^{* *}}\end{array}$ & $\begin{array}{c}-0.055 \\
{[0.091]}\end{array}$ & $\begin{array}{c}0.006 \\
{[0.009]}\end{array}$ & $\begin{array}{c}0.022 \\
{[0.012]}\end{array}$ & $\begin{array}{c}0.081 \\
{[0.034]^{*}}\end{array}$ & $\begin{array}{c}0.004 \\
{[0.007]}\end{array}$ & $\begin{array}{c}-0.021 \\
{[0.009]^{*}}\end{array}$ & $\begin{array}{c}0.001 \\
{[0.003]}\end{array}$ & $\begin{array}{c}0.012 \\
{[0.003]^{* *}}\end{array}$ & $\begin{array}{c}0.011 \\
{[0.006]}\end{array}$ & $\begin{array}{c}0.130 \\
{[0.068]}\end{array}$ \\
\hline \#Obs. & 255018 & 255018 & 255018 & 255018 & 254953 & 248438 & 255018 & 255018 & 255018 & 255007 & 242314 & 255018 \\
\hline R-squared & 0.7 & 0.6 & 0.52 & 0.76 & 0.79 & 0.72 & 0.6 & 0.69 & 0.82 & 0.61 & 0.59 & 0.54 \\
\hline $\begin{array}{l}\text { Test COHS= } \\
\text { 2Plan } / \mathrm{GMC}=0\end{array}$ & $\begin{array}{c}7.89 \\
0.000\end{array}$ & $\begin{array}{l}17.37 \\
0.000\end{array}$ & $\begin{array}{c}1.07 \\
0.344\end{array}$ & $\begin{array}{r}7.59 \\
0.001\end{array}$ & $\begin{array}{l}13.84 \\
0.000\end{array}$ & $\begin{array}{r}3.35 \\
0.035\end{array}$ & $\begin{array}{c}1.27 \\
0.282\end{array}$ & $\begin{array}{r}7.65 \\
0.001\end{array}$ & $\begin{array}{c}0.04 \\
0.959\end{array}$ & $\begin{array}{l}10.15 \\
0.000\end{array}$ & $\begin{array}{c}2.60 \\
0.074\end{array}$ & $\begin{array}{c}2.73 \\
0.065\end{array}$ \\
\hline Test COHS= & 0.24 & 0.61 & 2.08 & 9.24 & 12.63 & 0.09 & 1.54 & 13.96 & 0.01 & 0.11 & 0.36 & 0.71 \\
\hline 2Plan/GMC & 0.627 & 0.435 & 0.150 & 0.002 & 0.000 & 0.761 & 0.214 & 0.000 & 0.930 & 0.746 & 0.549 & 0.399 \\
\hline \multicolumn{13}{|c|}{ Panel C: Births Within +/- 3 years of Implementation of MMC Only } \\
\hline COHS & $\begin{array}{c}-0.011 \\
{[0.039]}\end{array}$ & $\begin{array}{c}-0.083 \\
{[0.027]^{* *}}\end{array}$ & $\begin{array}{c}0.761 \\
{[0.338]^{*}}\end{array}$ & $\begin{array}{c}0.079 \\
{[0.016]^{* *}}\end{array}$ & $\begin{array}{c}0.102 \\
{[0.025]^{* *}}\end{array}$ & $\begin{array}{c}0.087 \\
{[0.116]}\end{array}$ & $\begin{array}{c}0.006 \\
{[0.017]}\end{array}$ & $\begin{array}{c}0.128 \\
{[0.056]^{*}}\end{array}$ & $\begin{array}{c}0.003 \\
{[0.013]}\end{array}$ & $\begin{array}{c}0.016 \\
{[0.010]}\end{array}$ & $\begin{array}{c}0.039 \\
{[0.028]}\end{array}$ & $\begin{array}{c}0.208 \\
{[0.232]}\end{array}$ \\
\hline 2Plan/GMC & $\begin{array}{c}-0.026 \\
{[0.010]^{* *}}\end{array}$ & $\begin{array}{c}-0.042 \\
{[0.014]^{* *}}\end{array}$ & $\begin{array}{c}0.002 \\
{[0.181]}\end{array}$ & $\begin{array}{c}0.012 \\
{[0.015]}\end{array}$ & $\begin{array}{c}0.042 \\
{[0.014]^{* *}}\end{array}$ & $\begin{array}{c}0.136 \\
{[0.054]^{*}}\end{array}$ & $\begin{array}{c}0.000 \\
{[0.008]}\end{array}$ & $\begin{array}{c}0.006 \\
{[0.012]}\end{array}$ & $\begin{array}{c}-0.004 \\
{[0.006]}\end{array}$ & $\begin{array}{c}0.011 \\
{[0.006]}\end{array}$ & $\begin{array}{c}0.026 \\
{[0.013]^{*}}\end{array}$ & $\begin{array}{c}0.235 \\
{[0.130]}\end{array}$ \\
\hline \#Obs. & 115035 & 115035 & 115035 & 115035 & 115018 & 112517 & 115035 & 115035 & 115035 & 115034 & 109118 & 115035 \\
\hline R-squared & 0.83 & 0.77 & 0.73 & 0.87 & 0.88 & 0.85 & 0.78 & 0.84 & 0.9 & 0.77 & 0.76 & 0.72 \\
\hline $\begin{array}{l}\text { Test COHS= } \\
\text { 2Plan } / \mathrm{GMC}=0\end{array}$ & $\begin{array}{r}3.45 \\
0.032\end{array}$ & $\begin{array}{r}6.89 \\
0.001\end{array}$ & $\begin{array}{r}2.59 \\
0.075\end{array}$ & $\begin{array}{l}13.03 \\
0.000\end{array}$ & $\begin{array}{l}10.38 \\
0.000\end{array}$ & $\begin{array}{c}3.27 \\
0.038\end{array}$ & $\begin{array}{c}0.06 \\
0.939\end{array}$ & $\begin{array}{c}2.65 \\
0.071\end{array}$ & $\begin{array}{c}0.32 \\
0.728\end{array}$ & $\begin{array}{c}3.12 \\
0.044\end{array}$ & $\begin{array}{c}2.71 \\
0.066\end{array}$ & $\begin{array}{c}1.79 \\
0.167\end{array}$ \\
\hline Test COHS= & 0.15 & 2.59 & 4.49 & 9.74 & 5.24 & 0.17 & 0.12 & 4.70 & 0.29 & 0.24 & 0.19 & 0.01 \\
\hline 2Plan/GMC & 0.703 & 0.108 & 0.034 & 0.002 & 0.022 & 0.680 & 0.727 & 0.030 & 0.591 & 0.621 & 0.661 & 0.913 \\
\hline
\end{tabular}

